\title{
EFFECT OF QUALITY OF WORKING LIFE ON
}

\author{
PSYCHOLOGICAL WELL-BEING AND MARITAL
}

\section{SATISFACTION AMONG MARRIED RESIDENT FEMALES}

\section{AT FACULTY OF MEDICINE - ZAGAZIG UNIVERSITY}

\author{
By \\ Nofal HA and EL Maghawry HA \\ ${ }^{1}$ Department of Public Health and Preventive Medicine, Faculty of Medicine-Zagazig University. \\ Nofal HA: hananofal196@yahoo.com \\ ELMaghawryHA: halamf@yahoo.com
}

\begin{abstract}
Working women are exposed to many stressors especially in the medical field which affect their well being and marital satisfaction. Individual perception of high Work Life Balance (WLB) and sense of well being has become vital for any organization in order to ensure enhanced performance efficiency. Aim of work: To assess the effect of quality of working life on psychological wellbeing and marital satisfaction among married resident females and to assess the effect of psychological wellbeing on marital satisfaction. Materials and methods: A cross- sectional study was conducted on 100 married resident females in different clinical departments at Zagazig University hospitals. Standardized scales were used to gather information including the Quality of Work Life (QOWL) scale, Ryff's Psychological Well-Being (PWB) scale and Enrich Marital Satisfaction (EMS) scale along with semi-structured questionnaire for sociodemographic data. Results: This study showed that the majority of our sample (70.0\%) had low QOWL, 86.0\% with low psychological well being and $75.0 \%$ with poor marital satisfaction and there were statistical significant direct correlation between QOWL and psychological wellbeing \& marital satisfaction; also between psychological well being and marital satisfaction. Conclusion and recommendations: the results of this study attract the attention to the high work-stress situation among medical staff and the reciprocal effects of job satisfaction, psychological well being and marital satisfaction. These results should be considered by health policy decision makers when providing facilities such as educational programs for empowering couples, encourage periodic medical and health assessments of medical staff, and providing psychological and family consulting services at the workplace.
\end{abstract}


Key words: Quality of working life, Psychological well being, Marital satisfaction and Resident married females.

\section{Introduction}

Work-life balance is a broad concept, defined by different ways. The origins of research on work-life balance can be essentially traced back to studies on women because they had multiple roles as wife, mother, homemaker and employee. Expectations from employed women related to their family role are similar high compared to those who are unemployed or house wives (Rafatjah, 2011). This inter-role conflict is an important source of stress. The employed women have to find a balance between their different roles. Work life balance was initially known as work family conflict, defined as "a form of inter role conflict in which the role pressures from work and family domains are mutually incompatible in some respect" (Jayanthi and Vanniarajan, 2012).

Family-work conflict (FWC) is more likely to exert negative influences in the family domain, lead to lower life satisfaction and increase internal conflict within the family (Reddy et al., 2010).

Individual perception of high Work Life Balance (WLB) and sense of well being has become imperative for any organization in order to ensure enhanced performance efficiency, particularly in highly sensitive and responsible work. It is no wonder that the work life balance has attracted numerous researchers who attempt to investigate various factors influencing WLB, their interrelationship and possible outcomes of different levels of WLB prevailing among employees especially female doctors who are responsible for multiple duties (Poulose and Sudarsan, 2014).

\section{Aim of study}

To assess the effect of quality of working life on psychological wellbeing and marital satisfaction among married resident females and to assess the effect of psychological wellbeing on marital satisfaction.

\section{Materials and methods}

- Study design: It is a cross sectional study.

- Place and duration of the study: This study was conducted at different clinical departments of Zagazig University hospitals, Sharkia governorate, Egypt, during the duration from 1st December (2017) till 1st April (2018).

- Study sample: All married resident 
females who were working in clinical departments at Zagazig University hospitals, those who were married from at least one year and accept to participate in the study were included; they were 100 females.

\section{- Study methods:}

\section{- A self- administrated questionnaire} included 4 standardized tools:

Tool (1): It was developed by the researcher to assess the socio demographic characteristics of the studied married resident females. The questionnaire included age, working hours / week , age of marriage , residential area, income, number of children, husband job and work duration.

\section{Tool (2): The Quality of Work} Life (QOWL) scale: this scale was developed by Van laar et al., (2007) to assess some aspects of work life quality. This scale consists of 34 items divided in seven factors (domains) namely as follows: factor1, eight items: " employee engagement ", factor 2, five items: " control at work ", factor 3 , five items "home - work interface", factor 4, seven items:" general well- being", factor 5, two items " job and career satisfaction " factor 6, three items: “ working conditions " and factor 7, four items "stress at work".

\section{Scoring for tool 2:}

The overall scale uses likert scale which is composed of five points (strongly disagree- disagree- neutralagree- strongly agree).The possible total scores ranged from 34 points to 170 points. Higher scores will signify elevated degree of quality of work life. The total scores and subscale scores were calculated by using the raw scores.

\section{Tools (3): Ryff's Psychological Well-} being scales (PWB): It was developed by (Ryff and Keyes, 1995) to assess psychological wellbeing by using a series of 42 statements reflecting the six areas of psychological wellbeing: autonomy (7 items), environmental mastery (7 items), personal growth (7 items), positive relation with others (7 items), purpose in life (7 items) and self acceptance (7 items).

\section{Scoring for tool 3:}

The score ranging from 1 to 5 with indicating 1 strong disagreement and 5 indicating strong agreement. For each category, a high score indicates that a respondent has a mastery of that area in her life. On the other hand a low score shows that the respondent struggles to 
feel comfortable with the environment of job.

\section{Tool (4): ENRICH Marital} Satisfaction (EMS) scale developed by Fowers and Oslon (1993). The scale consists of 15 items; ten of the scale s items consist of 10 domains of marital quality. The other 5 items is composed of a marital conventionalization.

\section{Scoring for tool 4:}

Likert scale ranging from 1 indicates strong disagreement and 5 indicate strong agreement.

\section{Total score:}

\section{Quality of Work Life scale}

- Total score about factor 1 (employee engagement ) was 40

- Total score about factor 2 (control at work) was 25

- Total score about factor 3 (home work interface) was 25

- Total score about factor 4 (general well being ) was 35

- Total score about factor 5 (Job and career satisfaction) was 10

- Total score about factor 6 (working conditions) was 15

- Total score about factor 7 (stress at work) was 20

- Total score about Quality of Work Life was 170

\section{Psychological well being scale}

- Total score about the first statement (autonomy) was 35

- Total sore about the second statement ( environmental mastery) was 35

- Total score about the third statement (personal growth) was 35

- Total score about the fourth statement ( positive relation with others) was 35

- Total score about the fifth statement (purpose of life ) was 35

- Total score about the sixth statement ( self acceptance) was 35

- Total score about psychological well being was 210

\section{Enrich marital satisfaction scale}

- Total score about marital status was 50

- Total score about idealistic ( Id) distortion was 25

- Total score about marital satisfaction was 75

Adequacy of quality of working life, psychological wellbeing and marital satisfaction were as follows: cut off point 
is $60 \%$ where as: $>60 \%$ was considered high and $\leq 60 \%$ was considered low.

The questionnaire was translated from English to Arabic by expert translator, then back-translated by another expert one, and finally, the original and translated versions were compared by another bilingual expert to ensure validity. The reliability coefficient test (Cronbach's alpha) was $>0.72$ for all questions.

\section{Pilot study:}

A pilot study was conducted on $10 \%$ of the total studied married resident females to evaluate the content and clarity of the tools, as well as to estimate the time needed for data collection. The necessary modifications were performed; the results of pilot study were not included in the study.

\section{Consent}

A verbal consent was obtained from all participants after clarification of the aim of the study. Collected data was kept strictly confidential and for the sole purpose of the study.

\section{Ethical approval}

An official permission was obtained from Public Health department and from the director of Zagazig University hospitals to the head of each department after explaining the aim of the research to get the permission for data collection.

\section{Data management}

The collected data were organized, tabulated and statistically analyzed using SPSS programme version 19. For quantitative variables, mean and standard deviations were calculated and for qualitative data, numbers and percents were calculated. Correlation estimates the amount of dependency of one factor on the other, the closeness of the association is measured by the Pearson 'correlation coefficient ( $r$ ) and considered statistically significant when $\mathrm{p}$-value $\leq 0.05$. 


\section{Results}

Table (1): Socio-demographic characteristics of the studied group (No $=100$ ).

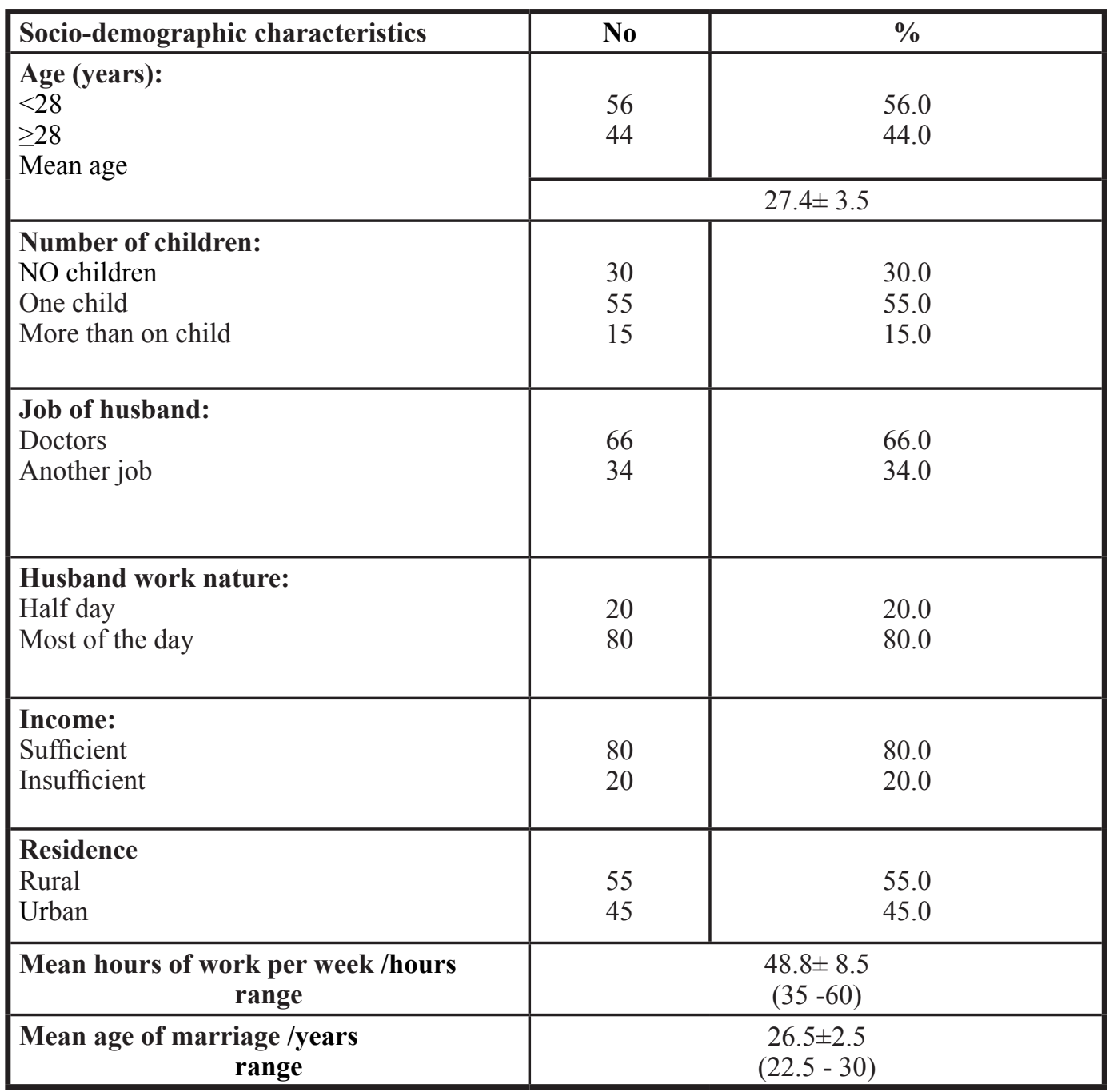

The study sample of female residents consisted of 100 married females about $56 \%$ of them were below 28 years old with mean age $27.4 \pm 3.5$ as seen in table (1), mean hours of work per week were $48.8 \pm 8.5$. The mean age of marriage was $26.5 \pm 2.5,55 \%$ of them have one child, about two thirds of them $(66 \%)$ their husbands were doctors, $80.0 \%$ of them their husbands work most of the day and their incomes were sufficient, $55 \%$ of them are coming from rural areas. 
Table (2): Quality of Working Life (QOWL) among the studied group (No =100).

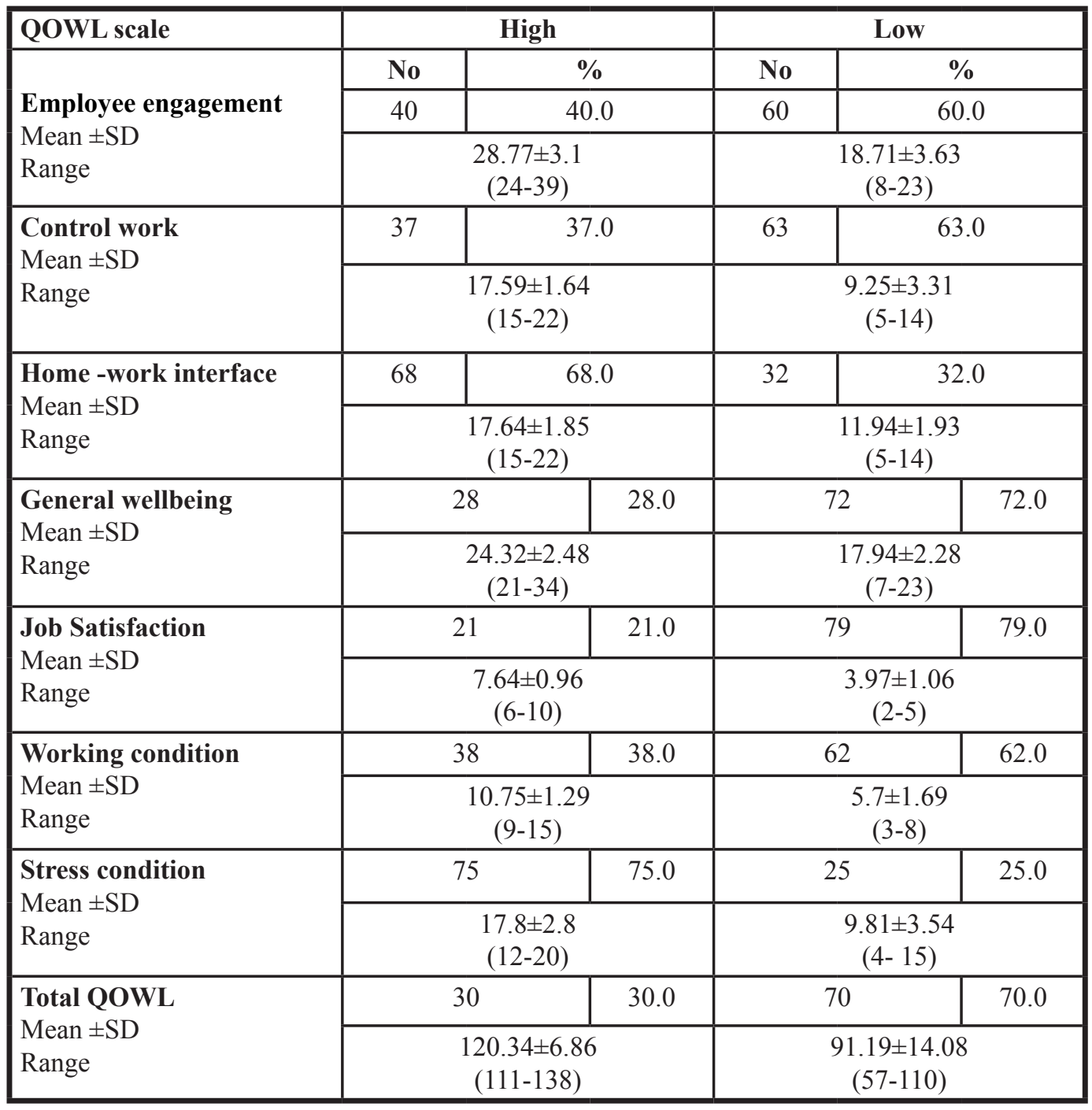

Table (2) showed that the majority of resident females were suffering from low employee engagement ( $60.0 \%$ ), low control of work(63.0\%), bad general well being(72.0\%), low job satisfaction(79.0\%) and bad work condition(62.0\%), in addition high home- work interface(68.0\%) and high stress condition(75.0\%). The majority of the studied group (70.0\%) had low QOWL with a mean $(91.19 \pm 14.08)$. 
Table (3): Psychological wellbeing among the studied group $($ No $=100)$.

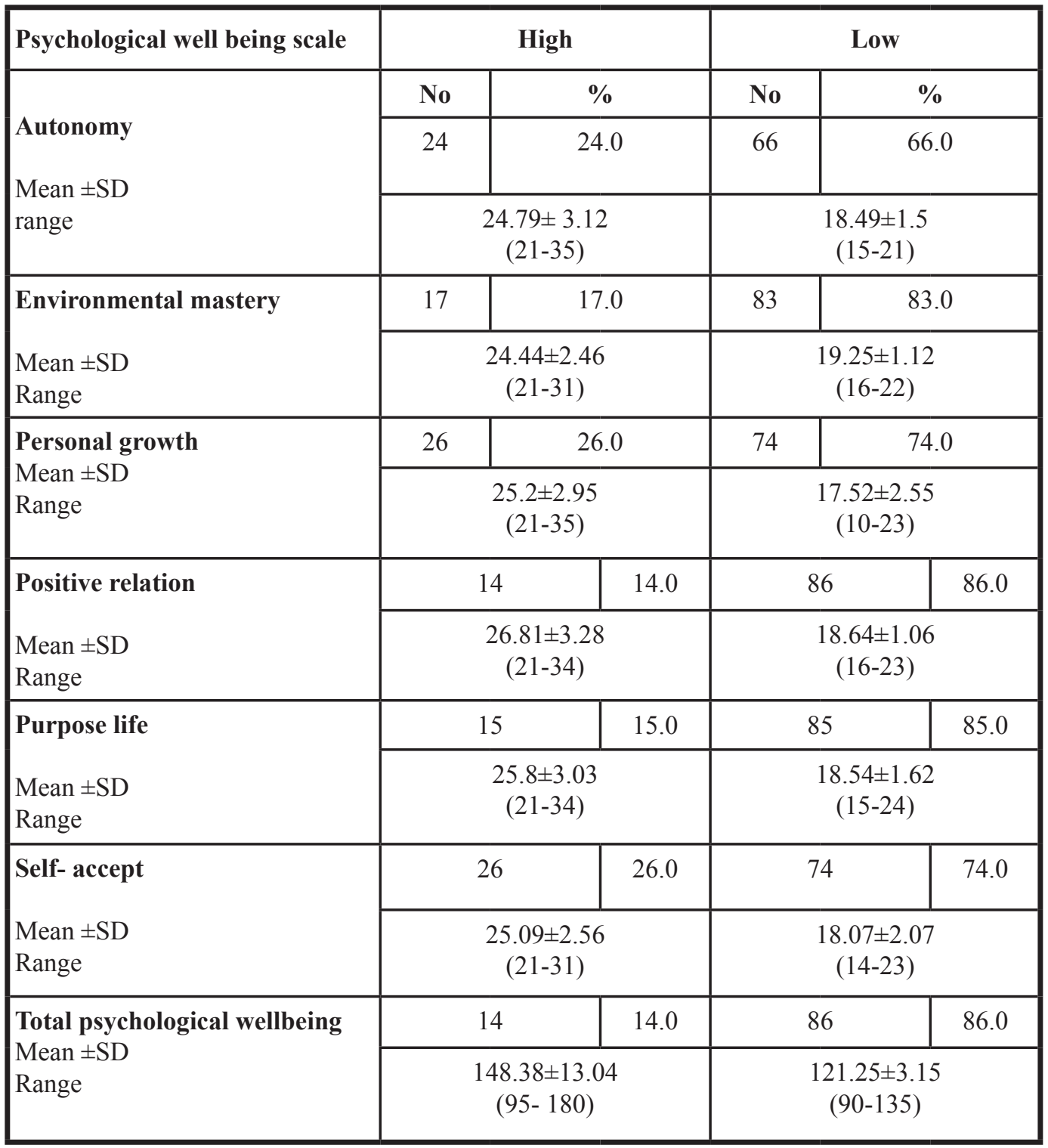

Table (3) showed that $86.0 \%$ of resident female doctors were suffering from low psychological wellbeing with mean $(121.25 \pm 3.15)$ and only $14.0 \%$ of them with good psychological wellbeing with a mean $(148.38 \pm 13.04)$. 
Table (4): Marital satisfaction among the studied group (No =100).

\begin{tabular}{|c|c|c|c|c|}
\hline Marital satisfaction scale & \multicolumn{2}{|c|}{ High } & \multicolumn{2}{|c|}{ Low } \\
\hline \multirow{3}{*}{$\begin{array}{l}\text { Mean } \pm \text { SD } \\
\text { Range }\end{array}$} & No & $\%$ & No & $\%$ \\
\hline & 24 & 24.0 & 76 & 76.0 \\
\hline & \multicolumn{2}{|c|}{$\begin{array}{c}18.52 \pm 2.29 \\
(15-25)\end{array}$} & \multicolumn{2}{|c|}{$\begin{array}{c}12.33 \pm 1.60 \\
(8-16)\end{array}$} \\
\hline \multirow[b]{2}{*}{$\begin{array}{l}\text { Mean } \pm \text { SD } \\
\text { Range }\end{array}$} & 35 & 35.0 & 65 & 65.0 \\
\hline & \multicolumn{2}{|c|}{$\begin{array}{c}38.26 \pm 4.29 \\
(30-49)\end{array}$} & \multicolumn{2}{|c|}{$\begin{array}{c}27.42 \pm 2.14 \\
(23-33)\end{array}$} \\
\hline \multirow[t]{2}{*}{ Total marital satisfaction } & 25 & 25.0 & 75 & 75.0 \\
\hline & \multicolumn{2}{|c|}{$\begin{array}{c}55.66 \pm 6.43 \\
(43-73)\end{array}$} & \multicolumn{2}{|c|}{$\begin{array}{c}41.36 \pm 4.1 \\
(32-54)\end{array}$} \\
\hline
\end{tabular}

Id distortion: Idealistic distortion.

Table (4) demonstrated that $75.0 \%$ of resident females had poor (Low) marital satisfaction with a mean $(41.36 \pm 4.1)$ and only $25.0 \%$ with good marital satisfaction with a mean $(55.66 \pm 6.43)$

Table (5): Correlation between QOWL, psychological wellbeing and marital satisfaction.

\begin{tabular}{|l|c|c|c|c|c|c|}
\hline & \multicolumn{2}{|c|}{$\begin{array}{c}\text { Psychological } \\
\text { wellbeing }\end{array}$} & \multicolumn{2}{c|}{ QOWL } & \multicolumn{2}{c|}{$\begin{array}{c}\text { Marital } \\
\text { satisfaction }\end{array}$} \\
\hline $\begin{array}{l}\text { Psychological } \\
\text { wellbeing }\end{array}$ & $\mathrm{r}$ & $\mathrm{p}$ & $\mathrm{r}$ & $\mathrm{p}$ & $\mathrm{r}$ & $\mathrm{p}$ \\
\cline { 2 - 7 } & & & .425 & $<0.001^{* *}$ & .512 & $<0.001^{* *}$ \\
\hline QOWL & .425 & $<0.001^{* *}$ & & & .218 & $0.005^{*}$ \\
\hline $\begin{array}{l}\text { Marital } \\
\text { satisfaction }\end{array}$ & .512 & $<0.001^{* *}$ & .218 & $0.005^{*}$ & & \\
\hline
\end{tabular}

QOWL: Quality of Working Life

*: Statistically significant at $\mathrm{p}$ value $<0.05$

**: Highly statistically significant at $\mathrm{p}$ value $<$ 0.001

Table (5) showed that highly significant positive correlation was present between psychological wellbeing and (QOWL \& marital satisfaction) (p value $<0.001$ ) and significant positive correlation between QOWL and martial satisfaction ( $\mathrm{p}$ value 0.005 ). 


\section{Discussion}

We were concerned in our study with married resident females working in clinical departments at Zagazig University hospitals regarding sociodemographic characteristics, quality of working life, psychological well being and marital satisfaction scales. It included 100 married female residents about $56 \%$ of them were below 28 years

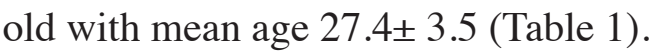

Mean hours of work per week were $48.8 \pm 8.5$ with range (35-60) (Table 1). El- shafei et al., 2018 noted that the mean hours of work among their study sample was $33.12 \pm 4.34$ with range (30 -60) hours per week. The mean hours of work per week in our study group are higher than El- shafei et al., 2018 because most of our sample was taken from the most junior residents.

The mean age of marriage was $26.5 \pm 2.5$ and $15.0 \%$ have more than one child (Table 1). The latter finding goes in the same line with Richter et al., 2014 who found that $14 \%$ of their sample study has more than one child.

Our study showed that the husbands of two thirds of the studied sample $(66 \%)$ were doctors, $80.0 \%$ worked most of the day outside home and their income was sufficient (Table1). These findings were in contrast to the results of El- shafei et al., 2018 who detected that $38.0 \%$ of physicians only had sufficient income.

The current study showed that $55 \%$ of participants were coming from rural areas (Table1), which is similar to the results detected El- shafei et al., 2018 who found that $60 \%$ of the participants were coming from rural areas.

Regarding QOWL, 60\% of the studied group had low employee engagement, $63 \%$ had low control work and $68 \%$ of them with home work interface (Table 2). These results were in accordance with Sachiko et al., 2015 who found that most of females in medical field (nurses and doctors) were unsatisfied due to low work control and home work interface because more than $60 \%$ of their day time was devoted to work and only less than $40 \%$ for their private life. Also these results were in agreement with Van laar et al., 2007 who found that $52 \%$ of their study sample was with poor work control and $63 \%$ with home work interface.

Only $28 \%$ of the studied sample had high general wellbeing, $21 \%$ had job satisfaction, $62 \%$ were suffering from stressful work condition, and $75 \%$ were always in stress (Table 2). These results 
agreed with Meera, 2012 who found that poor quality of infrastructure, workload, number of working hours, irregular shifts are the major stressors for all personnel working in the medical field which had significant impact on their QOL.

Also the present work findings were supported by the study carried out by Dehghanmehr et al., 2016 who reported that most of health care workers have low job satisfaction, only a third of participants were satisfied from their job.

The results of the current study showed that about $80 \%$ of the studied sample was unsatisfied (Table 2) which was lower than the results detected by Naziripour, 2007 in his work in Guilan governmental hospitals and found that $100 \%$ of his studied sample was unsatisfied with different degrees.

In the study conducted by Farajzadeh et al., 2016 showed that most of participants were unsatisfied with their jobs especially if there was under pressure and stressful working environment.

On the other hand the results of our study were in disagreement with Shabaninejad et al., 2012 who found that only $46 \%$ of physicians had low quality of working life while about $70 \%$ of our studied group was suffering from low QOWL (Table 2).

Our study showed that $86 \%$ of resident females were suffering from psychological wellbeing (Table 3). This agreed with the work done by Bhola, 2015 who found that $79 \%$ of working women in his studied group had multiple psychological/mental health problems. Also Rafatjah, 2011; in his study on gender stereotypes in Iran, found that the majority of respondents were complaining from emotional exhaustion, anxiety disorders and women find themselves in a very complicated situation. In addition, our findings were supported by Vicenta and Santiago (2007) who showed that doctors demonstrated poor psychological well-being.

The results of the current study were in disagreement with Madhuchandra and Srimathi (2016) who revealed that $84.5 \%$ of health care workers reported positive psychological wellbeing, while $15.5 \%$ had psychological distress. The majority of the respondents in the study reported that they were satisfied with their work.

As regarding marital satisfaction, the 
majority of our studied sample $(75.0 \%)$ had low marital satisfaction using Enrich Marital Satisfaction (EMS) scale and only $25 \%$ were satisfied (Table 4) . These results were in agreement with Richter et al.2014 who detected that $70 \%$ of female medical staff members in Tehran University hospitals were unsatisfied or moderately satisfied. But our study was in contrast to that of Warde et al., 1999 who reported that approximately half of the physicians in their studied sample were extremely or very satisfied with their marriages.

Marital satisfaction, psychological wellbeing and QOWL are related concepts that can affect each other, and lower satisfaction in marriage can lead to low psychological wellbeing and low QOWL among women (Table 5). The positive association between marital satisfaction and QOL in women was confirmed by the research findings done by Wickrama et al., 1997 and Bookwala 2011. Also Whisman et al., 2004 and Proulx et al., 2007 reported that marital satisfaction is positively linked to personal well being, including physical and psychological health.

Our findings in (Table 5) are in the same line with Maskowska, 1995 who found that quality of work affected most significantly psychological well-being of women: the higher the demands, the worse the well-being. Also Yami et al., 2011 on their work on health care workers in Jimma University specialized hospital, Southwest Ethiopia, showed that job satisfaction has a positive and significant relationship with marital satisfaction.

Our work showed that work-family conflict has direct relationship with marital satisfaction (Table 5). These findings agreed with the results obtained by Jessen, 2010 in his work about job satisfaction and social rewards in the social services. He concluded that work-family conflict has direct effect on job such as reduced both job and marital satisfaction.

\section{Conclusion and recommendations:}

The current study revealed that work-stress among medical staff had a negative impact on job satisfaction, psychological well being and marital satisfaction. These results should be considered by health policy decision makers when providing facilities such as educational programs for empowering couples (e.g. family education and stress management), increasing job satisfaction and reducing job stress (e.g., modified work schedules, system 
support, and daily child care facilities). Encourage periodic medical and health assessments of medical staff, and providing psychological and family consulting services at the workplace.

These results could also be applied by family social workers and family consultants to help and empower couples in improving marital relationships and QOL, especially among women.

The results of the present study can be applied on different levels (e.g., the individual, professional, and policy-maker levels) to improve individuals' mental and social health, family relationships (e.g., marital and parenting quality), and functioning in daily working life , thus improving the QOL of medical staff and other employed spouses.

\section{Conflict of interest}

The authors declare that they have no conflict of interests.

\section{Funding}

This research did not receive any specific grant from funding agencies in the public, commercial or not-for-profit sectors

\section{Acknowledgement}

The author wish to thank all participants of the study for their cooperation and help.

\section{References}

1-Bahola S (2015): Impact of Work-Life Imbalance on Health of Women. National Conference Reflection: Emerging Drift: 37-56. Available at http://www.indianmba.com/Occasional_Papers/ OP183/op183.

2-Bookwala J (2011): Marital quality as a moderator of the effects of poor vision.

J Gerontol Soc Sciences; 66:605-616.

3-Dehghanmehr S, Balouchi A, Shahdadi H and Bandadni E (2016): The Relationship between Job Satisfaction and Marital Satisfaction in Amir AlMomenin Hospital, Zabol, Iran. Der Pharmacia Lettre; 8 (13):251-55.

4- El-Shafei DA, Abdelsalam AE, Hammam RA and Elgohary H (2018): Professional quality of life, wellness education, and coping strategies among emergency physicians. Environ Sci Pollut R; 25 (9):9040-50.

5-Farajzadeh LR, Moghaddami NA, Abbasian P and Mohammadpour Z (2016): A Survey of Job Satisfaction among Health Sector Staff of Tabriz Taleghani Educational Hospital. Depiction of Health; 6(4): 32-9

6-Flowers BJ and Olson DH (1993): ENRICH Marital Satisfaction Scale: A brief research and clinical tool. J Fam Psychol; 7(2): 176-85.

7-Jayanthi B and Vanniarajan T (2012): Work-Life Imbalance among executives: A gender focuses. Global Management Review; 6(2): 24-35.

8- Jessen JT (2010): Job Satisfaction and Social Rewards in the Social Services. J Comp Soc Re; 5 (1): 1-18.

9-Sachiko M, Junko T, Yoshihiro A, Kazuo O and Yutaka K (2015): Impact of work-life imbalance on job satisfaction and quality of life among hospital doctors and nurses in Japan. Ind health; 53: 152-9.

10-Madhuchandra MK and Srimathi NL (2016): Psychological Well-being among Doctors and Nurses .The International Journal of Indian Psychology; 3(4):204-10. 
11-Maskowska Z (1995): Psychosocial Characteristics of Work and Family as a Determinant of Stress and Well-Being of Women: A Preliminary Study. In J Occup Env Heal; 8 (3): 215-22.

12-Meera V and Vazirani N (2012): A Comparative Study on Stress among workers in medical field in Private and Public Hospitals in Mumbai. BVIMR Management Edge; 5 (1): 46-52.

13- Naziripour AA (2007): Survey the level of job satisfaction among managers and supervisors in different units of Guilan governmental hospitals. Journal of Guilan University of Medical Sciences; 16(61): 65-73.

14-Poulose S and Sudarsan N (2014): Work Life Balance. IJAME 3 (2):1-17.

15-Proulx CM, Helms HM and Buehler C (2007): Marital quality and personal well-being: A MetaAnalysis. J Marriage Fam Rev; 69(3): 576-93.

16- Rafatjah M (2011): Changing gender stereotypes in Iran. Int J Womens Res; 1(1): 61-75.

17- Reddy NK, Vranda MN, Ahmed A, Nirmala BP and Siddaramu B (2010): Work-Life Balance among Married Women Employees. Indian J Psychol Med; 32(2):112-18.

18-Richter J, Rostami A and Ghazinour M (2014): Marital Satisfaction, Coping, and Social Support in Female Medical Staff. J Fam Issues; 8 (1): 11527.

19- Rostami A, Ghazinour M, Nygren L and Richter J (2013): Marital Satisfaction with a Special Focus on Gender Differences in Medical Staff in Tehran-Iran. J Fam Issues; 8(1): 115-27.

20- Ryff CD and Keyes CL (1995): The Structure of Psychological Well-Being Revisited. J Pers Soc
Psychol ; (69): 719-27.

21-Shabaninejad H, Arab M, Rashidian A, Zeraati H and Bahrami S (2012): Quality of Working Life of Physicians in Mazandaran. Hakim Research Journal; 15(2): 178- 84.

22-Van Laar DL, Edwards JA and Easton S (2007): The Work-Related Quality of Life Scale for Higher Education Employees. J Adv Nurs; 15(3):207-19 .

23-Van Laar DL, Edwards JA and Easton S (2007): The Work-Related Quality of Life Scale for health care workers. J Adv Nurs; 60(3):325-33.

24-Vicenta EA and Santiago PH (2007): Psychological well-being and psychosocial work environment characteristics among emergency medical and nursing staff. Stress and Health; 23 (3): 153-60.

25-Warde CM, Moonesinghe K, Allen W and Gelberg L (1999):Marital and parental satisfaction of married physicians with children. J Gen Intern Med; 14(3):157-65.

26- Whisman MA and Uebelacker LA (2004): Psychopathology and marital satisfaction: The importance of evaluating both partners. J Consult Clin Psych; 72(5): 830-38.

27- Wickrama KA, Lorenz FO, Conger RD, Elder J and Gelen H (1997): Marital quality and physical illness: A latent growth curve analysis. J Marriage Fam; 59:143-55.

28-Yami A, Hamza L, Hassen A, Jira C and Sudhakar M (2011): Job satisfaction and its determinants among health workers in Jimma University specialized hospital, Southwest Ethiopia. Ethiop J Health Sci; 21: 19-27. 